\title{
Carbonatite magmatism in subduction zones: Evidence from the Khanneshin volcano in Afghanistan FORREST HORTON
}

Woods Hole Oceanographic Institution

Presenting Author: horton@whoi.edu

Carbonatites are typically associated with intraplate magmatism. The Pliocene Khanneshin carbonatite volcano in southern Afghanistan is a rare exception. There, carbonatites erupted above the actively subducting Makran slab that reaches depths of $\sim 180 \mathrm{~km}$ beneath the Registan Desert [1]. Trace elements, stable isotopes (carbon, oxygen, and thallium: [2]), and radiogenic isotopes (strontium, neodymium, and lead: [3]) indicate that the Khanneshin carbonatites derived from subducted seafloor sediments of the Indus Fan. The inferred deposition age of the sedimentary precursors implies that subducted material recycled to and from mantle depths in less than 30 million years. Efficient carbon recycling via carbonatitic melts helps explain why global subduction zone carbon inputs are not balanced by volcanic arc outputs [4]. The Khanneshin volcano may be a rare surface expression of long-lived carbon reservoirs that form in rear-arc lithosphere; carbonatites elsewhere that contain isotopic evidence of recycling [5-7] may derive from such reservoirs that were reactivated by intraplate rifting or hotspot activity.

[1] Penney, et al. (2017), Geophysical Journal International 209, 1800-1830.

[2] Horton, Nielsen, Shu, Gagnon \& Blusztajn (2021), Geochemistry, Geophysics, Geosystems, e2020GC009472.

[3] Ayuso, et al. (2013), Journal of Geochemical Exploration $133,6-14$.

[4] Aiuppa, Fischer, Plank \& Bani (2019), Scientific Reports 9, 5442 .

[5] Hoernle, Tilton, Le Bas, Duggen \& Garbe-Schönberg (2002), Contributions to Mineralogy and Petrology 142, 520542.

[6] Hulett, Simonetti, Rasbury \& Hemming (2016), Nature Geoscience 9, 904.

[7] Amsellem, et al. (2020), Science Advances 6, eaba3269.

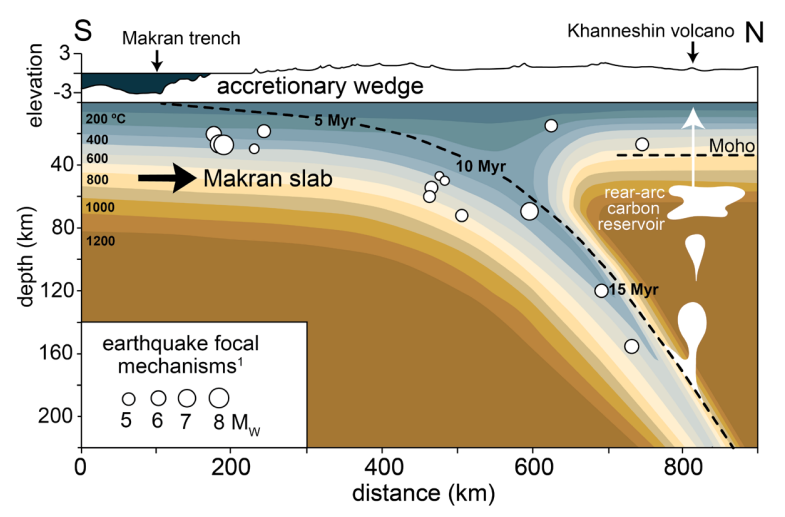

